ANNA TUROWSKA

ORCID 0000-0002-9115-9812

Uniwersytet Warszawski

\title{
STRES I EMOCJE STUDENTÓW ZARZĄDZANIA
}

ABSTRACT. Turowska Anna, Stres i emocje studentów zarzadzania [Stress and Emotions of Management Students]. Studia Edukacyjne nr 59, 2020, Poznań 2020, pp. 237-248. Adam Mickiewicz University Press. ISSN 1233-6688. DOI: 10.14746/se.2020.59.15

The subjects were 196 final-year students of The Warsaw School of Economics Faculty of Management. The purpose of the study was to measure the dominant strategy of coping with stress moderated by positive, negative and ambivalent emotions. This can be of significance in the management of staff and organizations under often unpredictable economic conditions.

Key words: students of management, stress, positive, negative and ambivalent emotions

\section{Wprowadzenie}

Stres towarzyszy ludziom przez całe życie. Jego oddziaływanie może być jednak różne. Stres o umiarkowanym natężeniu działa aktywizująco - pobudza myślenie. Zbyt wysokie jego natężenie obniża aktywność działania, prowadzi do porażki. Studenci ostatniego roku kierunku Zarządzanie zdają sobie sprawę, że w przyszłości to oni będą odpowiedzialni za organizowanie i kierowanie przedsiębiorstwem. Niewątpliwie chcieliby, żeby proces ten przebiegał jak najbardziej pomyślnie. Nie zawsze się to jednak udaje. Ważny jest wybór sposobów radzenia sobie ze stresem. To zaś zależy od wielu predyspozycji osobowościowych, jakimi dysponuje osoba ponosząca odpowiedzialność za rozwój Organizacji. Istotny jest tu rodzaj motywacji osiągnięć, samooceny, przekonanie, „czy ode mnie zależy sukces”, a także umiejętność współpracy z ludźmi. Każdy menedżer ma niezwerbalizowany obraz własnej osoby, który dotyczy sądów o sobie samym, uwzględniających własne możliwości i potrzeby. Rozważaniom tym zawsze towarzyszą emocje i one w dużej mierze decydują o wyborze dominującej strategii radzenia sobie ze stresem. W Polsce inicjato- 
rem badań nad stresem był psycholog Janusz Reykowski ${ }^{1}$. W nawiązaniu do teorii różnic indywidualnych i genetyki, tematykę tę podejmował Jan Strelau ${ }^{2}$. Problematykę stresu organizacyjnego opisał również Jan Felicjan Terelak ${ }^{3}$. Spośród zagranicznych badaczy stresu i radzenia sobie najwybitniejszym i najczęściej cytowanym, światowym autorytetem jest Richard Lazarus ${ }^{4}$ - twórca najbardziej popularnej koncepcji stresu w ujęciu fenomenologiczno-poznawczym. Richard Lazarus wraz z Susan Folkman ${ }^{5}$ kładą nacisk na znaczenie kontekstu sytuacyjnego i relacji jednostki z otoczeniem dla wszelkich form aktywności człowieka. Podejście fenomenologiczno-poznawcze polega na tym, że o uznaniu relacji za stresową rozstrzyga subiektywna ocena znaczenia tej relacji przez osobę w niej uczestniczącą. Proces oceniania obejmuje przede wszystkim te elementy relacji z otoczeniem, które są ważne dla dobrostanu jednostki. Dlatego, Richard Lazarus i Susan Folkman uważają, że „Stres jest to określona relacja między osobą a otoczeniem, która oceniana jest przez osobę jako obciążająca lub przekraczająca jej zasoby i zagrażająca jej dobrostanowi" ${ }^{\prime}$.

Natomiast radzenie sobie, według wyżej wymienionych autorów, definiowane jest jako „poznawcze i behawioralne wysiłki zmierzające do sprostania specyficznym wymogom zewnętrznym i/lub wewnętrznym, które w ocenie jednostki przekraczają możliwości, jakimi ona dysponuje"7.

Literatura przedmiotu wyodrębnia dwa rodzaje strategii radzenia sobie z sytuacją stresową: zadaniową - nastawioną na rozwiązanie problemu oraz emocjonalną - skierowaną na redukcję lęku lub innych stanów emocjonalnych, wynikających z zagrożenia ego jednostki. N.S. Endler i J.D.A. Parker ${ }^{8}$ wydzielają ze strategii emocjonalnej dodatkowo trzecią strategię - ucieczkową (np. używanie środków psychoaktywnych).

Nie każdy rodzaj emocji towarzyszący menedżerowi sprzyja decyzjom prowadzącym do sukcesu zarządzanej organizacji.

${ }^{1}$ J. Reykowski, Funkcjonowanie osobowości w warunkach stresu psychologicznego, Warszawa 1966, s. 223-274; tenże, Eksperymentalna psychologia emocji, Warszawa 1968, s. 64, 70, 381.

2 J. Strelau, Temperament a stres. Temperament jako czynnik moderujacy stresory, stan i skutki stresu oraz radzenie sobie ze stresem, [w:] Cztowiek w sytuacji stresu. Problemy teoretyczne i metodologiczne, red. I. Heszen-Niejodek, Z. Ratajczak, Katowice 1996, s. 88-130.

${ }^{3}$ J. Terelak, Stres organizacyjny: koncepcje, przyczyny, symptomy $i$ sposoby radzenia sobie, Warszawa 2005.

${ }^{4}$ R.S. Lazarus, Psychological stress and the coping process, New York 1966; tenże, The stress and coping paradigm, [w:] Competence and coping during adulthood, red. L.A. Bond, J.C. Rosen, Hanover 1980, s. 28-74.

${ }^{5}$ R.S. Lazarus, S. Folkman, Stress, appraisal and coping, New York 1984.

${ }_{6}$ Tamże, s. 19.

7 S. Folkman, R.S. Lazarus, The relationship between coping and emotion. Implication and research, Social Science and Medicine, 1988, 26, s. 310.

${ }^{8}$ N.S. Endler, J.D.A. Parker, Assessment of multidimensional coping: Task, emotion and avoidance strategies, Psychological Assessment, 1994, 6, s. 50-60. 
Na wybór strategii radzenia sobie z sytuacją trudną inaczej wpływają emocje pozytywne, inaczej negatywne, a jeszcze inaczej - ambiwalentne. Tak więc, emocje mogą stanowić filtr informacyjny, wykrywający co jest dobre, a co złe dla danego podmiotu9. Mogą też być uzupełnieniem deficytu informacyjnego.

Emocje negatywne stanowią sygnał informujący, że należy podjąć działanie interwencyjne usuwające zagrożenie ${ }^{10}$.

Emocje pozytywne sygnalizują z kolei, że reakcja podmiotu nie jest potrzebna ${ }^{11}$. Wielu autorów podkreśla korzystne działanie emocji pozytywnych $\mathrm{w}$ podejmowaniu optymalnych decyzji ${ }^{12}$.

Pomimo że dysponujemy wiedzą o dobroczynnym wpływie emocji pozytywnych na nasze funkcjonowanie i radzenie sobie $\mathrm{z}$ trudnościami, nie jesteśmy w stanie całkowicie wyeliminować z naszego życia emocji negatywnych. W sytuacji, kiedy emocje negatywne o zbyt dużym natężeniu wyraźnie przeważają nad emocjami pozytywnymi - wyzwalają stan utrudniający myślenie, objawiający się na przykład paraliżującym lękiem, depresją, frustracją i agresją. Taki przejaw negatywnych emocji ma destrukcyjny wpływ na funkcjonowanie człowieka i nie sprzyja oczywiście pokonywaniu napotykanych trudności w zarządzaniu organizacją.

Najczęściej jednak doświadczamy sytuacji wyzwalających emocje sprzeczne - ambiwalentne. Prowokują do nich na przykład środki masowego przeka$\mathrm{zu}$, informujące niekonsekwentnie o koniunkturze gospodarczej. Informacje te śledzą często osoby kończące studia i wiążące swoją zawodową przyszłość $\mathrm{z}$ organizacją i zarządzaniem ${ }^{13}$. Pojawia się potrzeba weryfikacji odbieranych informacji. Wielu autorów uważa, że racjonalnemu radzeniu sobie z trudnościami najbardziej wydaje się sprzyjać właśnie jednoczesne współpobudzenie emocji pozytywnych i negatywnych. Według J.T. Cacioppo i współpracowników ${ }^{14}$, współpobudzenie to jest wprawdzie czasowo raczej niestabilne,

${ }^{9}$ A.R. Damasio, Descarte's error: Emotion, reason and the human brain, New York 1994.

${ }^{10}$ D. Clark, Zachowania prospołeczne i antyspołeczne, Gdańsk 2005; N. Schwartz, G.L. Clore, Mood, misattribution and judgements of well-being: Informative and directive functions of affective states, Journal of Personality and Social Psychology, 1984, 45, s. 513-523.

${ }^{11}$ N. Schwartz, G.L. Clore, Mood, misattribution and judgements of well-being.

${ }^{12}$ L.G. Kiken, B.L. Fredrickson, Cognitive Aspects of Positive Emotions: A Broader View for Well-Being, [w:] The Happy Mind: Cognitive Contributions to Well-Being, red. M. Robinson, M. Eid, Switzerland 2017, s. 157-175; B.L. Fredrickson, T. Joiner, Reflections on Positive Emotions and Upward Spirals, Perspective on Psychological Science, 2018, 13(2), s. 194-199, https://doi. org/10.1177/1745691617692106; S. Folkman, J.T. Moskowitz, Stress, positive emotion, and coping, Current Directions in Psychological Science, 2000, 9, s. 115-118.

${ }_{13}$ A. Turowska, Radzenie sobie ze stresem u progu samodzielności życiowej osób kończacych studia wyższe, Uniwersytet Warszawski, 2013.

${ }_{14}$ J.T. Cacioppo, G.G. Berntson, Relationship between attitudes and evaluative space: A critical review, with emphasis on the separability of positive and negative substrates, Psychological Bulletin, 
nieprzyjemne i dysonansowe, niemniej może być warunkiem uruchomienia poznawczych mediatorów zdrowego radzenia. Przykładem tego jest zaangażowanie $\mathrm{w}$ stresowe wydarzenie i poszukiwanie w nim sensu ${ }^{15}$.

\section{Cel badań}

Dotyczył on ustalenia dominującej strategii radzenia sobie ze stresem pod wpływem emocji pozytywnych, negatywnych oraz współpobudzenia obydwu tych emocji (Eksperymenty I, II, III).

\section{Hipotezy badawcze}

Hipoteza 1. Wzbudzenie emocji pozytywnych istotnie podniesie poziom zadaniowej strategii radzenia sobie ze stresem.

Нipoteza 2. Wzbudzenie emocji negatywnych podwyższy poziom emocjonalnej i ucieczkowej strategii radzenia sobie ze stresem.

Hipoteza 3. Współpobudzenie emocji pozytywnych i negatywnych przyczyni się do nasilenia zadaniowej strategii radzenia sobie ze stresem.

\section{Osoby badane i metoda}

Przed rozpoczęciem badań uzyskano pozytywną opinię Komisji ds. Etyki Badań Naukowych, jak również zgodę Władz SGH na ich przeprowadzenie.

Badania realizowano w grupie 196 osób (122 kobiet i 74 mężczyzn), studentów V roku studiów magisterskich Szkoły Głównej Handlowej, kierunku Zarządzanie, których wiek sięgał 23 - 25 lat. Poproszeni studenci wzięli udział w badaniu dobrowolnym i anonimowym, trwającym około 30 minut. Zastosowano w nim manipulację eksperymentalną, której skuteczność zosta-

1994, 115, s. 401-423; J.T. Cacioppo, W.L. Gardner, G.G. Berntson, Beyond bipolar conceptualizations and measures: The case of attitudes and evaluative space, Personality and Social Psychology Review, 1997, 1, s. 3-25; J.T. Cacioppo, W.L. Gardner, G.G. Berntson, The affect system has parallel and integrative processing components: From follows function, Journal of Personality and Social Psychology, 1999,76 , s. 839-855.

${ }^{15}$ C.S. Carver, M.F. Scheier, J.K. Weintraub, Assessing Coping Strategies: A Theoretical Based Approach, Journal of Personality and Social Psychology, 1989, 2, s. 267-283; I.D. Rivkin, S.E. Taylor, The effects of mental simulation on coping with controllable stressful events. Personality and Social Psychology Bulletin, 1999, 25, s. 1451-1462; J.T. Larsen i in., Czerpanie korzyści z niepowodzenia: o zaletach wspótpobudzania emocji pozytywnych i negatywnych, [w:] Psychologia pozytywna, red. J. Czapiński, Warszawa 2004; T. Larsen, P. McGraw, The Case for Mixed Emotions, Social and Personality Psychology Compass, 2014, 8(6). 
ła opisana w pracach Vallachera, Reada i Nowaka, Krejtza oraz Turowskiej ${ }^{16}$. Manipulacja ta polegała na wypełnieniu formularza, w którym badana osoba miała napisać 5 zdań prezentujących sukcesy ostatnich pięciu lat studiów oraz 5 zdań odnośnie nadziei na przyszłość.

W grupie drugiej, w formularzu należało napisać 5 porażek oraz 5 obaw.

Trzecia grupa otrzymała do wypełnienia formularz dotyczący emocji ambiwalentnych.

Badanie składało się z dwóch części i przeprowadzone było w czterech grupach (trzy grupy eksperymentalne oraz jedna grupa kontrolna).

Czesść pierwsza badania, autorstwa A. Turowskiej, stanowiła manipulację eksperymentalną. Dotyczyła ona wzbudzenia emocji pozytywnych (Eksperyment I) oraz emocji negatywnych (Eksperyment II), a także emocji ambiwalentnych (Eksperyment III).

Czéść druga badania diagnozowała wybór dominującej strategii radzenia sobie ze stresem. Posłużono się tu kwestionariuszem CISS Endlera i Parkera ${ }^{17}$, przystosowanym do warunków polskich przez K. Wrześniewskiego ${ }^{18}$. Technika ta mierzy nasilenie wyboru strategii: zadaniowej, emocjonalnej, ucieczkowej. Wyniki wyboru dominującej strategii radzenia sobie ze stresem z trzech grup eksperymentalnych porównano z wynikami grupy czwartej - kontrolnej.

\section{Zmienne}

\section{Zmienne niezależne}

- pozytywne pobudzenie emocjonalne,

- negatywne pobudzenie emocjonalne,

- współpobudzenie emocji pozytywnych i negatywnych.

\section{Zmienne zależne}

- strategie radzenia sobie ze stresem:

- zadaniowa

- emocjonalna

- ucieczkowa

${ }^{16}$ R.R. Vallacher, S.I. Read, A. Nowak, The dynamic perspective in personality and social psychology, Personality and Social Psychology Review, 2002, 6(4), s. 264-273; K. Krejtz, Dynamika Ja. Regulacyjne funkcje globalnych własności Ja w strumieniu autorefleksji, Uniwersytet Warszawski, 2003; A. Turowska, Radzenie sobie ze stresem u progu samodzielności życiowej.

${ }_{17}$ N.S. Endler, J.D.A. Parker, Assessment of multidimensional coping: Task, emotion and avoidance strategies, Psychological Assessment, 1994, 6, s. 50-60.

${ }^{18} \mathrm{~K}$. Wrześniewski, M. Guzowska, Mechanizm obronny wyparcia a radzenie sobie ze stresem: Wybrane zagadnienia teorii i pomiaru, [w:] Teoretyczne i kliniczne problemy radzenia sobie ze stresem, red. I. Heszen-Niejodek, Poznań 2002, s. 109-131; K. Wrześniewski, Opracowanie i adaptacja polskiej wersji kwestionariusza CISS-S N.S. Endlera i J.D.A. Parkera, Uniwersytet Warszawski, 2002. 


\section{Wyniki badań własnych}

Wybór strategii radzenia ze stresem $\mathrm{w}$ warunkach sytuacyjnie wzbudzonych emocji przedstawiono w formie wykresów i tabel. Obliczeń statystycznych dokonano za pomocą pakietu SPSS 21.
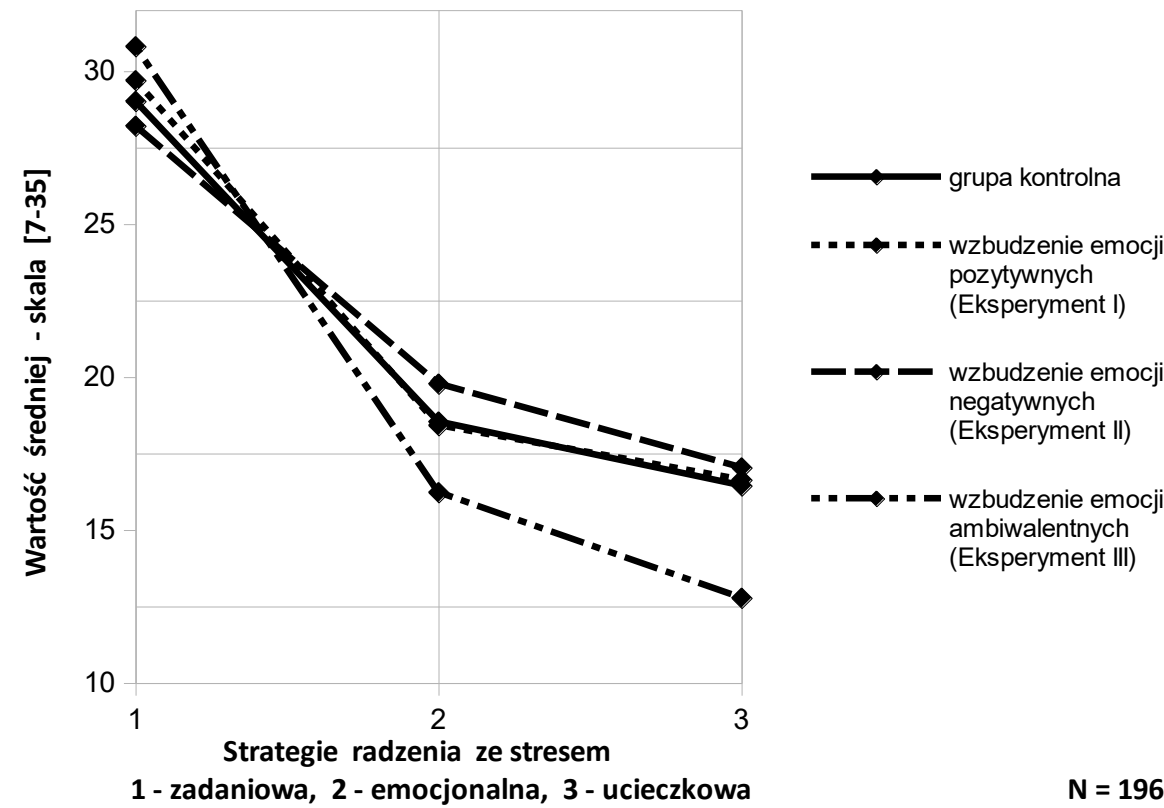

Ryc. 1. Studenci ostatniego roku SGH kierunek Zarządzanie - strategie radzenia ze stresem a emocje

U przyszłych absolwentów SGH kierunku Zarządzanie wzbudzenie emocji pozytywnych nie spowodowało istotnych różnic w wyborze strategii radzenia ze stresem. Brak istotnych zmian zauważa się również w przypadku wzbudzenia emocji negatywnych. Przy wykluczeniu z analizy warunków jednoczesnego współpobudzenia emocji pozytywnych i negatywnych, wynik analizy wariancji dla warunków pozytywnych oraz negatywnych jest nieistotny statystycznie:

$\mathrm{F}(4,292)=1,89 ;$ eta $^{2}=0,02 ;$ n.i.

Istotne statystycznie zmiany $\mathrm{w}$ wyborze dominującej strategii radzenia ze stresem zaobserwowano u studentów SGH tylko w warunkach współpobudzenia zarówno emocji pozytywnych, jak i negatywnych. W porównaniu 
z grupą kontrolną, istotnie obniżył się poziom strategii emocjonalnej, jak również ucieczkowej.

Bez względu na rodzaj wzbudzonych emocji, dominującą strategią jest jednak strategia zadaniowa.

Wynik analizy wariancji: $F(6,384)=7,32 ; \mathrm{p}<0,001 ;$ eta $^{2}=0,11$.

Tabela 1

Studenci ostatniego roku SGH - kierunek Zarządzanie.

Strategie radzenia sobie ze stresem a rodzaj wzbudzonych emocji. Statystyki opisowe

\begin{tabular}{|c|c|c|c|c|}
\hline $\begin{array}{l}\text { Strategia ra- } \\
\text { dzenia sobie } \\
\text { ze stresem }\end{array}$ & Rodzaj emocji & Średnia & $\begin{array}{l}\text { Odchylenie } \\
\text { standardowe }\end{array}$ & $\mathrm{N}$ \\
\hline \multirow{5}{*}{ Zadaniowa } & neutralne (grupy kontrolne) & 29,02 & 2,77 & 48 \\
\hline & pozytywne & 29,70 & 2,19 & 50 \\
\hline & negatywne & 28,21 & 4,18 & 51 \\
\hline & współpobudzenie emocji & 30,81 & 2,42 & 47 \\
\hline & & & & Ogółem 196 \\
\hline \multirow{5}{*}{ Emocjonalna } & neutralne (grupy kontrolne) & 18,54 & 4,96 & 48 \\
\hline & pozytywne & 18,42 & 5,09 & 50 \\
\hline & negatywne & 19,78 & 4,79 & 51 \\
\hline & współpobudzenie emocji & 16,23 & 3,96 & 47 \\
\hline & pozytywnych i negatywnych & & & Ogótem 196 \\
\hline \multirow{4}{*}{ Ucieczkowa } & neutralne (grupy kontrolne) & 16,45 & 4,71 & 48 \\
\hline & pozytywne & 16,64 & 4,80 & 50 \\
\hline & negatywne & 17,04 & 4,75 & 51 \\
\hline & $\begin{array}{l}\text { współpobudzenie emocji po- } \\
\text { zytywnych i negatywnych }\end{array}$ & 12,78 & 2,93 & $\begin{array}{c}47 \\
\text { Ogótem } 196\end{array}$ \\
\hline
\end{tabular}

Dane przedstawione w tabeli 1 potwierdzają, że bez względu na rodzaj sytuacyjnie wzbudzonych emocji, najczęściej wybieraną strategią radzenia sobie jest strategia zadaniowa.

Współpobudzenie emocji pozytywnych i negatywnych istotnie obniży częstość wyboru niekorzystnej strategii emocjonalnej i ucieczkowej osób badanych. 
Tabela 2

Studenci ostatniego roku SGH kierunek Zarządzanie - strategie radzenia ze stresem a emocje. Wyniki testu post hoc. Porównania parami cz. 1

\begin{tabular}{|c|c|c|c|c|}
\hline $\begin{array}{c}\text { Strategia } \\
\text { radzenia } \\
\text { sobie ze } \\
\text { stresem }\end{array}$ & $\begin{array}{c}\text { (I) Ro- } \\
\text { dzaj } \\
\text { emocji }\end{array}$ & (J) Rodzaj emocji & $\begin{array}{l}\text { Różnica śred- } \\
\text { nich (I-J) }\end{array}$ & Istotność \\
\hline \multirow{6}{*}{$\begin{array}{l}\text { Zadanio- } \\
\text { wa }\end{array}$} & \multirow{3}{*}{$\begin{array}{c}\text { neutral- } \\
\text { ne }\end{array}$} & pozytywne &,- 679 & 1,000 \\
\hline & & negatywne & ,805 & 1,000 \\
\hline & & $\begin{array}{l}\text { współpobudzenie emocji pozytyw- } \\
\text { nych i negatywnych }\end{array}$ & $-1,788^{*}$ & ,026 \\
\hline & \multirow{2}{*}{$\begin{array}{l}\text { pozy- } \\
\text { tywne }\end{array}$} & negatywne & 1,484 & ,085 \\
\hline & & $\begin{array}{l}\text { współpobudzenie emocji pozytyw- } \\
\text { nych i negatywnych }\end{array}$ & $-1,109$ & 612 \\
\hline & $\begin{array}{l}\text { nega- } \\
\text { tywne }\end{array}$ & $\begin{array}{l}\text { współpobudzenie emocji pozytyw- } \\
\text { nych i negatywnych }\end{array}$ & $-2,593^{*}$ & ,000 \\
\hline \multirow{6}{*}{$\begin{array}{c}\text { Emocjo- } \\
\text { nalna }\end{array}$} & \multirow{3}{*}{$\begin{array}{c}\text { neutral- } \\
\text { ne }\end{array}$} & pozytywne & 122 & 1,000 \\
\hline & & negatywne & $-1,243$ & 1,00 \\
\hline & & $\begin{array}{l}\text { współpobudzenie emocji pozytyw- } \\
\text { nych i negatywnych }\end{array}$ & 2,308 & 111 \\
\hline & \multirow{2}{*}{$\begin{array}{l}\text { pozy- } \\
\text { tywne }\end{array}$} & negatywne & $-1,364$ & ,894 \\
\hline & & $\begin{array}{l}\text { współpobudzenie emocji pozytyw- } \\
\text { nych i negatywnych }\end{array}$ & 2,186 & 145 \\
\hline & $\begin{array}{l}\text { nega- } \\
\text { tywne }\end{array}$ & $\begin{array}{l}\text { współpobudzenie emocji pozytyw- } \\
\text { nych i negatywnych }\end{array}$ & $3,550 *$ & ,002 \\
\hline \multirow{6}{*}{$\begin{array}{l}\text { Ucieczko- } \\
\text { wa }\end{array}$} & \multirow{3}{*}{$\begin{array}{l}\text { neutral- } \\
\text { ne }\end{array}$} & pozytywne &,- 182 & 1,000 \\
\hline & & negatywne & $-0,883$ & 1,000 \\
\hline & & $\begin{array}{l}\text { współpobudzenie emocji pozytyw- } \\
\text { nych i negatywnych }\end{array}$ & $3,853^{*}$ & ,000 \\
\hline & \multirow{2}{*}{$\begin{array}{l}\text { pozy- } \\
\text { tywne }\end{array}$} & negatywne &,- 399 & 1,000 \\
\hline & & $\begin{array}{l}\text { współpobudzenie emocji pozytyw- } \\
\text { nych i negatywnych }\end{array}$ & $3,853^{*}$ & ,000 \\
\hline & $\begin{array}{l}\text { nega- } \\
\text { tywne }\end{array}$ & $\begin{array}{c}\text { współpobudzenie emocji pozytyw- } \\
\text { nych i negatywnych }\end{array}$ & $4,252^{*}$ & ,000 \\
\hline
\end{tabular}


Tabela 3

Studenci ostatniego roku SGH kierunek Zarządzanie - strategie radzenia ze stresem a emocje. Wyniki testu post hoc. Porównania parami cz. 2

\begin{tabular}{|c|c|c|c|c|}
\hline Rodzaj emocji & $\begin{array}{c}\text { Strategia radzenia } \\
\text { sobie } \\
\text { ze stresem }(\mathrm{I})\end{array}$ & $\begin{array}{c}\text { Strategia radzenia } \\
\text { sobie } \\
\text { ze stresem }(J)\end{array}$ & $\begin{array}{l}\text { Różnica } \\
\text { średnich } \\
\quad(\mathrm{I}-\mathrm{J})\end{array}$ & $\begin{array}{l}\text { Istot- } \\
\text { ność }\end{array}$ \\
\hline \multirow{3}{*}{ Neutralne } & \multirow{2}{*}{ zadaniowa } & emocjonalna & $10,479 *$ & ,000 \\
\hline & & ucieczkowa & $12,563^{*}$ & ,000 \\
\hline & emocjonalna & ucieczkowa & $2,083^{*}$ & ,002 \\
\hline \multirow{3}{*}{ Pozytywne } & \multirow{2}{*}{ zadaniowa } & emocjonalna & $11,280^{*}$ &, 000 \\
\hline & & ucieczkowa & $13,060^{*}$ & ,000 \\
\hline & emocjonalna & ucieczkowa & 1,780 & ,053 \\
\hline \multirow{3}{*}{ Negatywne } & zadaniowa & emocjonalna & $8,431^{*}$ & ,000 \\
\hline & & ucieczkowa & $11,176^{*}$ & ,000 \\
\hline & emocjonalna & ucieczkowa & $2,761^{*}$ & ,001 \\
\hline \multirow{3}{*}{$\begin{array}{c}\text { Współpobu- } \\
\text { dzenie emocji } \\
\text { pozytywnych } \\
\text { i negatyw- } \\
\text { nych }\end{array}$} & \multirow{2}{*}{ zadaniowa } & emocjonalna & $14,574^{*}$ & ,000 \\
\hline & & ucieczkowa & $18,021^{*}$ & ,000 \\
\hline & emocjonalna & ucieczkowa & $3,447^{*}$ & ,000 \\
\hline
\end{tabular}

Wyniki przedstawione w tabeli 3 potwierdzają dominowanie strategii zadaniowej nad wyborem strategii emocjonalnej i ucieczkowej.

\section{Podsumowanie}

Bez względu na rodzaj wzbudzonych emocji, w grupie badanych studentów SGH kierunku Zarządzanie dominuje zadaniowa strategia radzenia sobie ze stresem. Wzbudzenie emocji pozytywnych nie wpłynęło istotnie na podniesienie poziomu zadaniowej strategii radzenia ze stresem. Nie potwierdziła się zatem Hipoteza 1 autorki, nawiązująca do badań Barbary Fredrikson.

Studenci Zarządzania nie zareagowali również na wzbudzenie emocji negatywnych. Nie potwierdziła się także Hipoteza 2, pomimo sugestii Clarka, Schwartza i Clore. Być może badania wymienionych autorów przeprowadzone były na innej populacji studentów. 
Wyraźnie potwierdziła się jednak Hipoteza 3, zakładająca, że jednoczesne wzbudzenie emocji pozytywnych i negatywnych przyczyni się do wzrostu poziomu strategii zadaniowej. $W$ tej grupie badanych istotnie obniżył się poziom strategii emocjonalnej i ucieczkowej. Wyniki te są zgodne z sugestiami Larsena, McGraw, Cacioppo, Hemenovera, Norrisa i innych.

Zatem, jednoczesne aktywizowanie zarówno emocji pozytywnych, jak i negatywnych, a także tolerowanie behawioralnej ambiwalencji mogą prowadzić do trwałych rezultatów emocjonalnych, wspomagających skupienie się na problemie i poradzenie sobie $\mathrm{z}$ poważnymi stresami $\mathrm{w}$ zarządzaniu organizacją.

\section{BIBLIOGRAFIA}

Cacioppo J.T., Berntson G.G., Relationship between attitudes and evaluative space: A critical review, with emphasis on the separability of positive and negative substrates, Psychological Bulletin, 1994, 115.

Cacioppo J.T., Gardner W.L., Berntson G.G., Beyond bipolar conceptualizations and measures: The case of attitudes and evaluative space, Personality and Social Psychology Review, 1997, 1.

Cacioppo J.T., Gardner W.L., Berntson G.G., The affect system has parallel and integrative processing components: From follows function, Journal of Personality and Social Psychology, 1999, 76.

Carver C.S., Scheier M.F., Weintraub J.K., Assessing Coping Strategies: A Theoretical Based Approach, Journal of Personality and Social Psychology, 1989, 2.

Clark D., Zachowania prospołeczne i antyspołeczne, Gdańskie Wydawnictwo Psychologiczne, Gdańsk 2005.

Damasio A.R., Descarte's error: Emotion, reason and the human brain, Avon Books, New York 1994.

Endler N.S., Parker J.D.A., Assessment of multidimensional coping: Task, emotion and avoidance strategies, Psychological Assessment, 1994, 6.

Folkman S., Lazarus R.S., Stress, appraisal and coping process, McGraw-Hill, New York 1984.

Folkman S., Lazarus R.S., The relationship between coping and emotion. Implication and research, Social Science and Medicine, 1988, 26.

Folkman S., Lazarus R.S., Coping as a mediator of emotion, Journal of Personality and Social Psychology, 1988, 54.

Folkman S., Moskowitz J.T., Stress, positive emotion, and coping, Current Directions in Psychological Science, 2000, 9.

Fredrickson B.L., Joiner T., Reflections on Positive Emotions and Upward Spirals, Perspective on Psychological Science, 2018, 13(2); https:/ / doi.org/10.1177/1745691617692106

Fredrickson B.L., Cultivating positive emotions to optimize health and well-being, Prevention and Treatment, 2000, 3; http://journals.apa.org.prevention [30.06.2018].

Fredrickson B.L., Positivity, Crown Publishers, New York 2009.

Grinker R.R., Spiegel J.P., Men under stress, McGraw-Hill, New York 1945.

Gollan J.K., Hoxha D., Hunnicut-Ferguson K., Norris C.J., Rosebrock L., Sankin L., Cacioppo J., Twice the negativity bias and half the positivity offset: Evaluative responses to emotional 
information in depression, Journal of Behaviour Therapy and Experimental Psychiatry, 2016, 52.

Kiken L.G., Fredrickson B.L., Cognitive Aspects of Positive Emotions: A Broader View for Well -Being, [w:] The Happy Mind: Cognitive Contributions to Well-Being, red. M. Robinson, M. Eid, Springer, Cham, Switzerland 2017.

Krejtz K., Dynamika Ja. Regulacyjne funkcje globalnych wtasności Ja w strumieniu autorefleksji, (praca doktorska) Wydział Psychologii, Uniwersytet Warszawski, 2003.

Larsen J.T., McGraw P., The Case for Mixed Emotions, Social and Personality Psychology Compass, 2014, 8(6).

Larsen J.T., Hemenover S.H., Norris C.J., Cacioppo J.T., Czerpanie korzyści z niepowodzenia: o zaletach wspótpobudzania emocji pozytywnych i negatywnych, [w:] Psychologia pozytywna, red. J. Czapiński, Wydawnictwo Naukowe PWN, Warszawa 2004.

Lazarus R.S., Psychological stress and the coping proces, McGraw-Hill, New York 1966.

Lazarus R.S., The stress and coping paradigm, [w:] Competence and coping during adulthood, red. L.A. Bond, J.C. Rosen, University Press of New England, Hanover 1980.

Lazarus R.S., Coping theory and research: Past, present and future, Psychosomatic Medicine, 1993, 55.

Lazarus R.S., From psychological stress to the emotions: A history of changing outlooks, Annual Review of Psychology, 1993, 44.

Lazarus R.S., Folkman S., Stress, appraisal and coping, Springer, New York 1984.

Reykowski J., Funkcjonowanie osobowości w warunkach stresu psychologicznego, PWN, Warszawa 1966.

Reykowski J., Eksperymentalna psychologia emocji, Książka i Wiedza, Warszawa 1968.

Reykowski J., Osobowość a trwaty stres, PZWL, Warszawa 1971.

Rivkin I.D., Taylor S.E., The effects of mental simulation on coping with controllable stressful events, Personality and Social Psychology Bulletin, 1999, 25.

Schwartz N., Clore G.L., Mood, misattribution and judgements of well-being: Informative and directive functions of affective states, Journal of Personality and Social Psychology, 1984, 45.

Strelau J., Temperament a stres. Temperament jako czynnik moderujący stresory, stan $i$ skutki stresu oraz radzenie sobie ze stresem, [w:] Człowiek w sytuacji stresu. Problemy teoretyczne i metodologiczne, red. I. Heszen-Niejodek, Z. Ratajczak, Wydawnictwo Uniwersytetu Śląskiego, Katowice 1996.

Terelak J., Stres organizacyjny: koncepcje, przyczyny, symptomy i sposoby radzenia sobie, Oficyna Wydawnicza WSM, Warszawa 2005.

Turowska A., Radzenie sobie ze stresem u progu samodzielności życiowej osób kończących studia wyższe (praca doktorska), Wydział Psychologii, Uniwersytet Warszawski, 2013.

Vallacher R.R., Read S.I., Nowak A., The dynamic perspective in personality and social psychology, Personality and Social Psychology Review, 2002, 6(4).

Wrześniewski K., Styl życia a zdrowie. Wzór zachowania, Wydawnictwo Instytutu Psychologii PAN, Warszawa 1993.

Wrześniewski K., Pomiar radzenia sobie ze stresem - wybrane zagadnienia, Promocja Zdrowia. Nauki Społeczne i Medycyna, 1996, III, 8-9.

Wrześniewski K., Style a strategie radzenia sobie ze stresem. Problemy pomiaru, [w:] Człowiek w sytuacji stresu. Problemy teoretyczne i metodologiczne, red. I. Heszen-Niejodek, Z. Ratajczak, Wydawnictwo Uniwersytetu Śląskiego, Katowice 1996.

Wrześniewski K., Psychologiczne uwarunkowania powstawania i rozwoju chorób somatycznych, [w:] Psychologia. Podręcznik akademicki, t. 3, red. J. Strelau, Gdańskie Wydawnictwo Psychologiczne, Gdańsk 2000. 
Wrześniewski K., Opracowanie i adaptacja polskiej wersji kwestionariusza CISS-S N.S. Endlera i J.D.A. Parkera, Wydział Psychologii, Uniwersytet Warszawski, 2002.

Wrześniewski K., Guzowska M., Mechanizm obronny wyparcia a radzenie sobie ze stresem. Wybrane zagadnienia teorii i pomiaru, [w:] Teoretyczne i kliniczne problemy radzenia sobie ze stresem, red. I. Heszen-Niejodek, Stowarzyszenie Psychologia i Architektura, Poznań 2002. 